\title{
NÉCROSE PANCRÉATIQUE INFECTIEUSE DES SALMONIDÉS: ÉTAT DES CONNAISSANCES CONCERNANT LES VIRUS ET LES POSSIBILITÉS DE LUTTE CONTRE LA MALADIE.
}

\author{
M. DORSON \\ Laboratoire d'Ichtyopathologie, INRA, \\ Route de Thiverval, 78850 THIVERVAL-GRIGNON (France)
}

\section{RÉ SUMÉ}

Cet article fait la synthèse des connaissances concernant le virus de la N.P.I. et les conditions de développement de la maladie ainsi que les essais de vaccination en insistant sur ce qui peut avoir une incidence pratique. Les virus de la N.P.I. et les virus apparentés présentent une variété qui croît avec l'étude de nouvelles souches: cette variété porte à la fois sur les propriétés biologiques et antigéniques des virus et est compliquée par la sélection aisée in vitro de variants différant notablement du virus d'origine. Il devient de plus en plus malaisé de placer les virus isolés sur le terrain dans les sérotypes "classiques". L'épidémiologie, et en particulier le portage et la transmission du virus, font l'objet d'un développement correspondant à l'acuité du problème en France. La truite Arc-en-Ciel élimine bien mieux le virus que l'Omble de fontaine, et la transmission verticale n'a rien d'automatique. Elle doit certainement se faire selon des mécanismes différents dont certains sont sensibles aux procédés de désinfection des œufs. L'étude du rôle de l'âge et de la température sur la maladie montre clairement que des températures supérieures à $15^{\circ} \mathrm{C}$ réduisent son incidence, et que la période pendant laquelle l'alevin est sensible à cette maladie peut s'exprimer en degrés $x$ jours L'interférence entre N.P.I. et Septicémie Hémorragique Virale est signalée.

Les essais thérapeutiques rapportés dans la littérature ne permettent pas d'espérer une application dans l'avenir proche. La liste des espèces de Salmonidés dont la sensibilité à la maladie est certaine actuellement est très restreinte, et il semble acquis que le Saumon Atlantique y est réfractaire. Jusqu'à présent la vaccination par virus tué n'a été possible que par injection, tandis que rares ont été les essais encourageants enregistrés avec des souches virales "atténuées"

\section{Infectious Pancreatic Necrosis of Salmonids: present status of knowledge concerning the viruses and the possibilities of controlling the disease.}

\section{SUMMARY}

This paper reviews the state of knowledge concerning IPN virus, the factors influencing on mortalities caused by the disease and vaccination, and stresses the points which are relevant from a practical viewpoint. IPN viruses and related viruses display a variety which is growing as new strains are studied : this variety lies on biological as well as antigenic properties and is complicated by the easy in vitro selection of variants differing from stem virus. It is becoming more and more difficult to place viruses isolated from the field in "classical" serotypes. The epidemiology, especially carrier state and transmission of virus, has received a special attention due to the importance of the problem in France. Rainbow trout eliminates the virus much better than Brook trout, and it appears that vertical transmission does not occur a utomatically. Vertical transmission must be achieved through different ways, and in some cases it can be avoided by egg desinfection. The severity of the disease is lowered at temperatures above $15^{\circ} \mathrm{C}$, and the period during which fry is susceptible to the disease can be expressed in day $x$ degrees. Interference between IPN and Viral Hemorrhagic Septicaemia is pointed out. Several chemicals have been checked for effectiveness for the treatment of IPN disease but have not led to any practical use. The list of the Salmonid species which are undoubtedly susceptible to the disease is short, and Atlantic Salmon can be considered as refractory. Up to now, fry have been vaccinated with killed virus only by injection, but some rare positive results have been gained with a non pathogenic strain. 


\section{INTRODUCTION}

WOOD, SNIESKO et YASUTAKE (1955) donnèrent le nom de Nécrose Pancréatique Infectieuse des Salmonidés à une maladie des alevins d'omble de fontaine (Salvelinus fontinalis Mitchill) nommée auparavant "entérité catarrhale aigue " par Mc GONIGLE (1940) dont ils décrivirent les principaux signes cliniques : nage avec rotation autour d'un axe horizontal, distension de l'abdomen, tube digestif vide d'aliment et empli de mucus, présence fréquente de déjections muqueuses à l'anus. L'Histologie révélait une nécrose remarquable du pancréas exocrine. L'étiologie virale de cette maladie fut démontrée par WOLF et al. (1960). La position systématique du virus a suivi diverses péripéties avec le temps et les auteurs, et il a été proposé (DOBOS et al., 1979) la création d'un nouveau groupe (Les birnaviridael pour accueillir les quelques virus qui partagent avec celui de la NPI les caractéristiques suivantes: virions nus de forme icosahédrique (Fig. 1) avec un diamètre de $60 \mathrm{~nm}$ environ, génome constitué d'un acide ribonucléique double brin bisegmenté. La Nécrose Pancréatique Infectieuse a été découverte dans tous les pays élevant des salmonidés et où ont été réalisés des contrôles virologiques. En France, elle fut mise en évidence sur des critères histopathologiques par BESSE et de KINKELIN (1965) et l'isolement des premières souches virales en provenance de France fut effectué par WOLF et QUIMBY (1971). Son incidence exacte sur la salmoniculture française est mal connue, mais de toute façon inférieure à celle des septicémies hémorragıques virales du fait que la NPI n'atteint que les alevins.

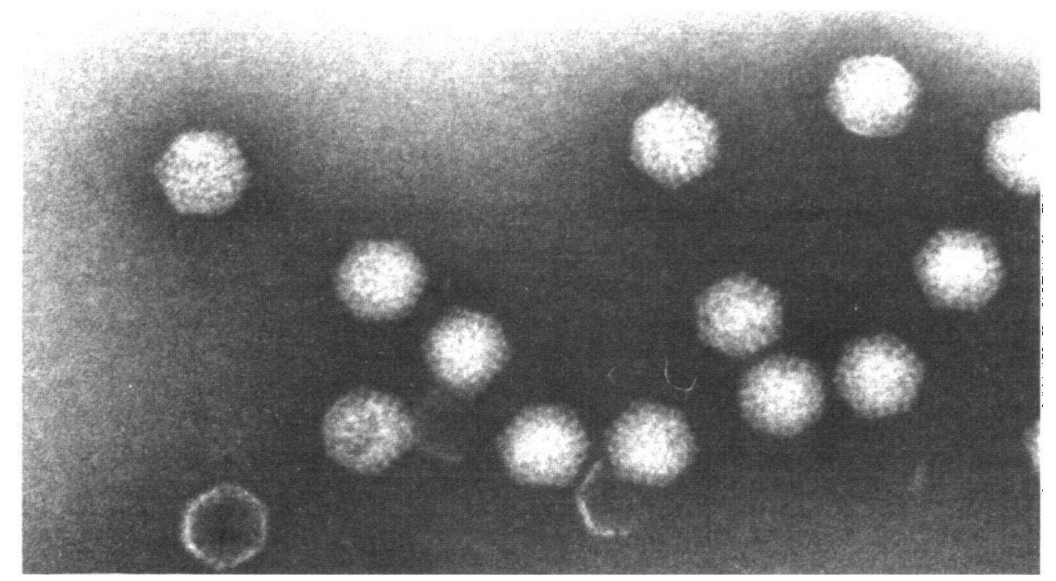

Figure 1 : Virus de la Nécrose Pancréatique Infectieuse observé au microscope électronique après coloration négative (cliché J. COHEN).

Cet article tente à la fois de faire une brève synthèse des nombreux travaux publiés depuis la découverte du virus et de présenter les résultats récents obtenus par notre laboratoire sur des souches européennes, en privilégiant ce qui nous paraît avoir une importance pratique quant à la salmoniculture

\section{LES VIRUS}

\subsection{Varièté et plasticité.}

Il est frappant de constater la complexité atteinte actuellement par le "monde" des virus de la NPI, après l'isolement d'un nombre croissant de souches virales. La première souche isolée, déposée à l'American Type Culture Collection, permit de définir le premier sérotype. ATCC VR 299 avec lequel a été réalisée la majorité des travaux concernant le virus ou la maladie mais dont certaines souches virales isolées par la suite aux USA différaient notablement (WOLF et al., 1968 a). En Europe furent rapidement définis les sérotypes Ab et Sp (VESTERGARD-JORGENSEN et KEHLET, 1971) qui diffèrent non seulement en séroneutralisation par un immunsérum de lapin, mais en possibilité de croissance sur diverses cellules de poisson en culture et par le pouvoir pathogène. De grandes variations de ce pouvoir pathogène suivant les souches virales et les souches de poissons ont été signalées par WOLF(1972). Aujourd'hui la sérologie des virus de la NPI atteint une complexité extrême (voir plus loin) avec la définition de 3 groupes majeurs, mais aussi la découverte de virus de la NPI, ou de virus apparentés chez de nombreuses espèces de poissons appartenant aux familles les plus diverses et chez 
des représentants de plusieurs embranchements d'invertébrés (HILL et WAY, 1980). On passe ainsi à des virus qui ne méritent plus le nom de virus de la NPI, tant que leur pouvoir pathogène pour les poissons n'est pas démontré.

Le virus VR 299 présente en culture cellulaire une grande plasticité (SCHERRER et COHEN, 1975 ; NICHOLSON. THORNE et JANICKI, 1979), et nous avons montré qu'un virus pathogène du type $\mathrm{Sp}$, isolé en pisciculture et cultivé en cellules de Truite (lignée RTG 2. WOLF et QUIMBY, 1962), perdait son pouvoir pathogène au bout de quelques passages et acquérait une surprenante sensibilité au sérum de truite normal (Tableau 1) (DORSON, de KINKELIN et TORCHY, 1975). Le support de la neutralisation du virus est une protéine totalement différente des anticorps (DORSON, 1977 a) et dont le rôle exact pour le poisson reste inconnu.

\begin{tabular}{|c|c|c|}
\cline { 2 - 3 } \multicolumn{1}{c|}{} & Mortalités & Titre neutralisant \\
\hline "Sauvage" & $80 \%$ & $<20$ \\
\hline Variant & $15 \%$ & 7.000 \\
\hline
\end{tabular}

Tableau 1 : Mortalités provoquées en 40 jours chez des alevins de truite Arcen-Ciel ágés de 6 semaines par un virus de la $\mathbf{N}$.P.I. isolé en pisciculture (souche "sauvage") et le variant obtenu par 14 passages in vitro en cellules de Truite RTG 2, avec les effets (titre neutralisant) d'un même sérum de truite normal sur les deux virus (D'après DORSON, CASTRIC et TORCHY, 1978).

Le virus "sauvage" pathogène et le virus "atténué" ne peuvent être distingués en séroneutralisation par un sérum de lapin, et ne diffèrent que très peu par leurs propriétés de croissance en culture cellulaire (DORSON, CASTRIC et TORCHY, 1978). Ce phénomène a été retrouvé par B.J. HILL (communication personnelle) sur des souches de Grande-Bretagne, par VESTERGARD-JORGENSEN (communication personnelle) sur des souches Danoises, par AHNE (1978) en Allemagne, et peut être considéré comme général, tout au moins pour les souches du type $\mathrm{Sp}$

\subsection{Culture et identification du virus.}

Sur 61 lignées cellulaires de poisson actuellement répertoriées, au moins 21 sont sensibles au virus de la NPI(WOLF et MANN, 1980). Si on se limite aux sérotypes les plus étudiés, et aux systèmes cellulaires couramment utilisés pour le diagnostic, on constate que les souches Sp et ATCC Vr 299 se multiplient sur cellules de truites RTG 2, et sur cellules de cyprinidés FHM (GRAVELL et MALSBERGER, 1965) ou EPC (FIJAN, à paraitre), tandis que la souche $A b$ ne se multiplie pas sur les cellules de cyprinidés, ainsi que certaines souches nord-américaines (NICHOLSON. THORNE et JANICKI, 1979). Toutes les souches se répliquent bien de $10^{\circ}$ à $18^{\circ} \mathrm{C}$ (production virale de l'ordre de $10^{8}$ unités formant plage (ufp) par $\mathrm{ml}$ ). La température supérieure à partir de laquelle la production chute brutalement (de $90 \%$ ) est de l'ordre de $19-20^{\circ} \mathrm{C}$ pour Sp, environ $24^{\circ}$ pour Ab et ATCC VR 299.

Le virus est extrait du matériel pathologique (alevins morts, rein antérieur, rate ou mème cerveau des truitelles et adultes) parbroyage suivi d'une mise en suspension dans du milieu de culture qui est ensuite clarifié par centrifugation avant d'être déposé sur des cellules sensibles. L'effet cytopathogène (E.C.P.) caractéristique (plages de cellules s'allongeant en fuseau avant de subir la lyse) peut être observé dès $48 \mathrm{~h}$ après l'inoculation à $14^{\circ} \mathrm{C}$ (Fig. 2). Le comptage des plages de lyse permet d'apprécier le nombre d'u.f.p. d'une suspension virale, et surtout d'observer sa réduction par séroneutralisation, après mélange avec le sérum d'un animal (lapin en général) qui a été préalablement immunisé par des injections du virus. Le virus peut aussi être directement mis en évidence sur des animaux malades par immunofluorescence (PIPER. NICHOLSON et DUNN, 1973) ou fixation du complément (FINLAY et HILL, 1975). 


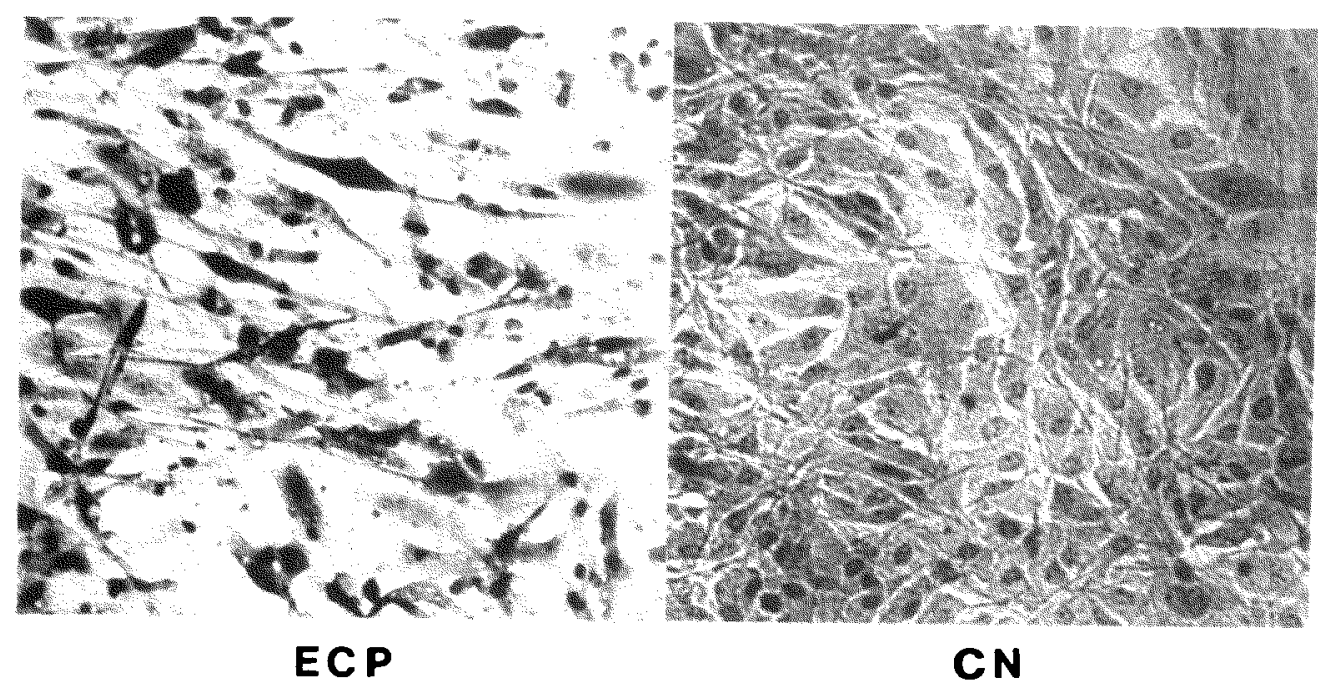

Figure 2 : Effet cytopathogène (ECP) provoqué en $48 \mathrm{~h}$ à $14^{\circ}$ par le virus de la NPI sur des cellules RTG 2.CN : cellules normales.

La sérologie des virus de la NPI et des virus apparentés a fait l'objet de travaux importants, parfois contradictoires, desquels il ressort une impression de grande complexité. Les raisons de cette complexité sont multiples: la réelle diversité des souches de virus, la variabilité dans la réponse de lapins différents à l'injection d'une même suspension virale tant en titre qu'en spécificité (il a été montré par VESTERGARD. JORGENSEN, 1972, que le type d'adjuvant employé pour l'immunisation influait sur la spécificité), enfin le manque de coordination entre les différentes équipes scientifiques. En effet le résultat d'une séroneutralisation dépend de la qualité de la préparation virale utilisée, de la technique employée et de bien d'autres facteurs.

Trois souches virales diffèrent notablement en sérologie et ont été définies au début de l'histoire de la NPI : la première souche américaine étudiée par WOLF et al., (1960) répertoriée comme souche de référence (ATCC VR 299), et deux souches européennes définies par VESTERGARD- JORGENSEN et KEHLET (1971). Ces souches ont été utilisées par la suite comme représentants de trois groupes dans lesquels les auteurs (HILL et WAY, 1980; NICHOLSON et POCHEBIT, 1981; MAC DONALD et GOWER, 1981) s'efforçaient de placer chaque nouvelle souche isolée. On est arrivé ainsi à trois groupes de plus en plus artificiels, dans lesquels la neutralisation des souches virales par un sérum anti-sérotype peut varier de 1 à 10 , avec des souches situées à la frontière entre deux groupes. Les souches européennes semblent jusqu'à présent n'appartenir qu'aux sérotypes $\mathrm{Ab}$ et $\mathrm{Sp}$, mais les premières souches françaises étudiées par WOLF et QUIMBY (1971) et considérées alors comme très différentes sérologiquement du VR 299 ont été récemment placées dans ce groupe par MAC DONALD et GOWER (1981).

\subsection{Résistance du virus}

Divers travaux ont été consacrés à la sensibilité du virus de la NPI à diverses conditions physico-chimiques, surtout pour des souches nord-américaines (DESAUTELS et MAC KELVIE, 1975; MAC KELVIE et DESAUTELS, 1975; TU et al., 1975) mais aussi des souches européennes (BAUDOUY, 1976). Comparé aux autres virus de salmonidés (les rhabdovirus, dont le virus de la Septicémie Hémorragique Virale), le virus de la NPI apparaît beaucoup plus résistant. En particulier dans de l'eau minérale à pH neutre le virus possède encore un pouvoir infectieux $11 / 10.000$ du nombre d'unités formant plage initiales) au bout de 50 jours à $14^{\circ}$ et de 330 jours à $4^{\circ}$. En eau de rivière sa conservation est encore meilleure, et il se conserve aussi fort bien dans la vase ou adsorbé sur les végétaux aquatiques. II résiste très bien auxpH acides (jusqu'à pH 2), mais beaucoup moins bien aux $\mathrm{pH}$ basiques. Sa résistance à la dessication est bonne: à $20^{\circ} \mathrm{C}$ et dans les conditions hygrométriques ambiantes on détecte encore le pouvoir infectieux au bout de 6 semaines. A $60^{\circ}$ il reste encore $20 \%$ des unités formant plage au bout d'une demi-heure. Quant à sa résistance aux rayons ultraviolets, elle est au moins 30 fois supérieure à celle du virus de la SHV (MAISSE, DORSON et TORCHY, 1981). II en est de même pour 
I'inactivation par le formol : il faut des doses dix fois supérieures pour inactiver le virus de la NPI (1/400, $16 \mathrm{~h})$ que pour inactiver celui de la SHV. Il faut pour le détruire entièrement en 30 minutes au moins 40 ppm de chlore libre (DESAUTELS et MAC KELVIE, 1975). Les iodophores (Wescodine, Betadine, Romeiod) inactivent bien le virus de la NPI, mais les doses nécessaires dépendent de la concentration initiale en particules virales, ainsi que de la présence de matières organiques qui réduisent leur efficacité. Pour les plus fortes concentrations en particules virales, il faut $16 \mathrm{mg} /$ ( (AMEND et PIETSCH, 1972 ; ELLIOT et AMEND, 1978) a $35 \mathrm{mg} /$ (DESAUTELS et MAC KELVIE, 1975) pour I'inactivation totale en $5 \mathrm{~min} .25 \mathrm{mg} / \mathrm{I}$ semble constituer un minimum surtout si le pH est basique (de $\mathrm{pH} 6$ à pH 8,6 l'efficacité est divisée par 4) et si le milieu liquide est riche en matières organiques.

\subsection{Porteurs et transmission du virus.}

Il fut remarqué très tôt que les survivants de NPI pouvaient rester porteurs à vie, et que le virus pouvait être extrait de divers organes et identifié comme il a été décrit plus haut (WOLF et QUIMBY, 1967). La détermination de la fréquence de porteurs dans une population donnée est importante pour apprécier les risques de transmission. Le tableau 2 résume les résultats disponibles. On peut observer que :

Tableau 2 : Résumé des données disponibles concernant la fréquence des porteurs de N.P.I. dans les échantillons de populations de Salmonidés contaminés.

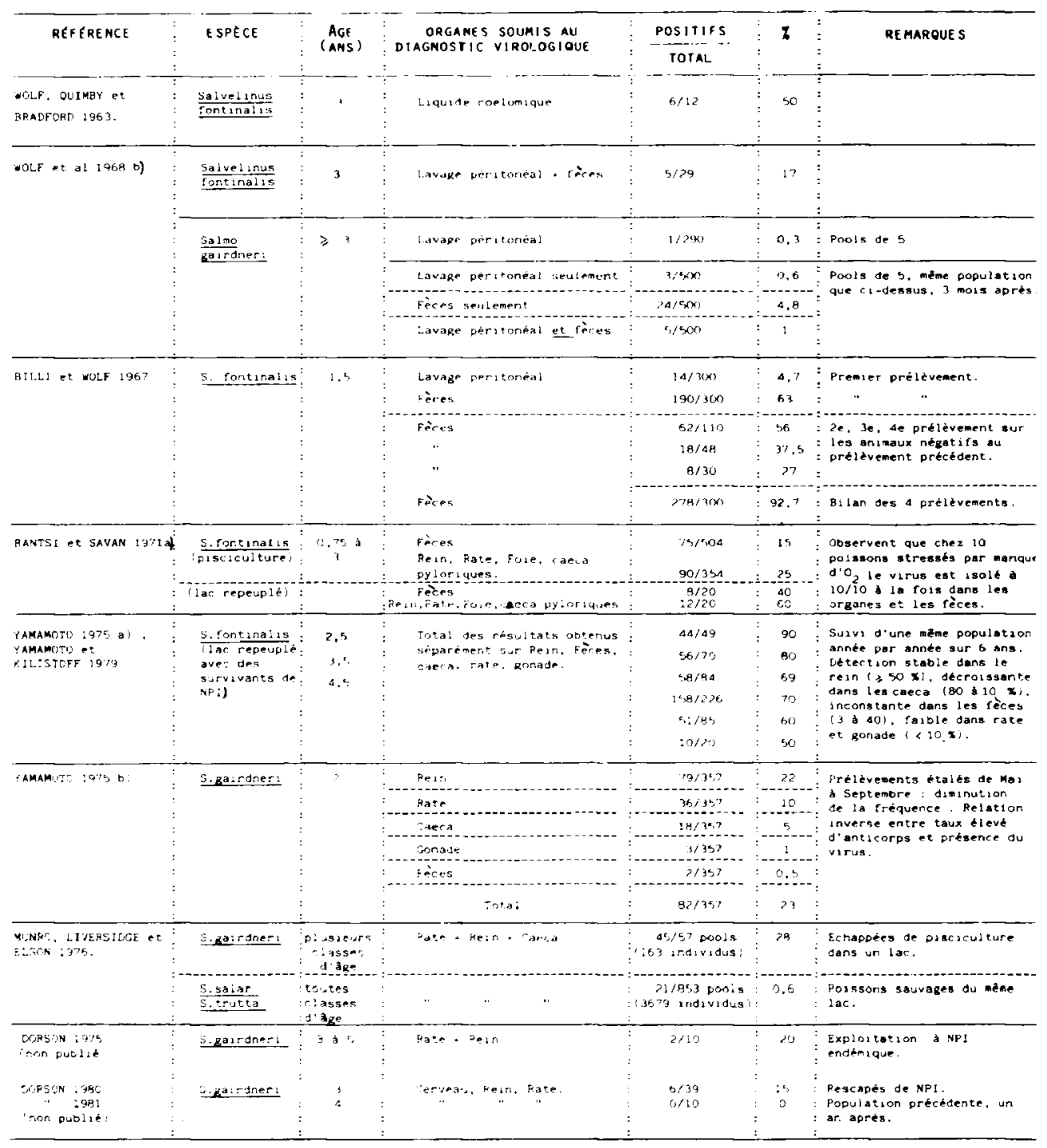


- La fréquence des porteurs détectés est en général plus élevée chez les ombles de fontaine que chez les truites Arc-en-Ciel pour lesquelles un échantillon plus important est nécessaire pour donner une garantie d'absence du virus dans un cheptel

- Le portage "à vie" est relativement fréquent, surtout chez la première espèce

- Le rein antérieur reste l'organe où le virus est le plus fréquemment isolé. Cependant il peut être isolé du cerveau alors qu'il n'est pas détectable ailleurs (J.CASTRIC et M. DORSON, résultats non publiés).

- Le virus est excrété dans les fèces, mais sa détection y est moins fréquente que dans les organes hématopoiétiques. Cependant la détection dans les fèces peut se faire avec une fréquence maximum chez des poissons stressés par hypoxie (FRANTSI et SAVAN, 1971 a)

Le sérodiagnostic (recherche dans le sérum des anticorps neutralisant spécifiquement le virus) est possible et a fait l'objet d'évaluations. Chez l'omble de fontaine il a été observé que les survivants de NPI (VR 299), même porteurs de virus, présentaient des titres en anticorps bas ou indétectables tandis que les truites Arc-enCiel semblaient de meilleurs producteurs danticorps (WOLF et QUIMBY, 1969; YAMAMOTO, 1975 a). Pour les virus européens de type Sp l'enquête sérologique n'est possible qu'à condition d'utiliser pour les tests un virus n'ayant subi que peu de passages en culture cellulaire (DORSON, de KINKELIN et TORCHY, 1975). Nous avons pu observer que les anticorps apparaissaient tôt après l'infection (de l'ordre de 3 semaines) et pouvaient en général être détectés plus d'un an après celle-ci. Cependant nous n'avons pas pu mettre en évidence une relation constante entre taux d'anticorps et détection du virus. Si la présence d'anticorps chez une truite signifie à coup sûr une expérience passée du virus pour ce poisson, leur absence ne peut être considérée comme une garantie absolue (Tableau 3).

Tableau 3 : Relation entre isolement du virus (cerveau, rein et rate) et présence d'anticorps (plus de $50 \%$ de neutralisation au $1 / 100$ ) chez 39 truites Arc-en-Ciel âgées de 3 ans, survivantes de N.P.I.

\begin{tabular}{|c|c|c|}
\hline \multicolumn{2}{|c|}{$\begin{array}{l}\text { Situation virologique } \\
\text { et sérologique }\end{array}$} & \multirow{2}{*}{$\begin{array}{c}\text { Nombre } \\
\text { d'individus }\end{array}$} \\
\hline $\begin{array}{l}\text { Présence } \\
\text { du virus }\end{array}$ & $\begin{array}{c}\text { Présence } \\
\text { d'anticorps }\end{array}$ & \\
\hline+ & + & 5 \\
\hline 0 & + & 11 \\
\hline+ & 0 & 1 \\
\hline 0 & 0 & 20 \\
\hline
\end{tabular}

La transmission verticale de la NPI par l'œuf était observée dès 1957 (SNIESZKO, WOOD et YASUTAKE), et en 1963 WOLF, QUIMBY et BRADFORD mettaient en évidence le portage du virus par les géniteurs: le virus était présent dans le liquide coelomique émis avec les ovules chez 7 des 12 femelles de 3 ans examinées, mais dans 3 échantillons d'ovules seulement. D'autre part ces auteurs observaient déjà le développement de la maladie dans un lot d'alevins bien que le virus $n$ 'ait pas pu être mis en évidence sur les œufs en incubation, et posaient la question qui reste au centre du problème de la transmission de la NPI : où se trouve le virus " dans" l'œuf? En 1957 SNIESZKO, WOOD et YASUTAKE puis en 1976 BULLOCK et al, confirmant de nombreuses observations, établissaient en effet que la désinfection des œufs ne coupait pas la transmission: si de nombreuses unités virales sont présentes dans le fluide coelomique et à la surface de l'œuf, une partie reste inaccessible aux désinfectants, donc sous (ou dans) la coque de l'œuf. Ces virions plus ou moins "internes" sont 
suffisamment rares pour échapper fréquemment au diagnostic, bien que FIJAN et GIORGETTI (1978) aient isolé le virus dans des échantillons d'œufs pris dans 2 lots qui furent par la suite frappés par la maladie.

Les observations de terrain ont souvent semblé confirmer que la désinfection classique des œufs aux iodophores ( $50 \mathrm{mg} / \mathrm{l}$ d'iode actif) coupe bien la transmission des rhabdoviroses (en France la Septicémie Hémorragique Virale), mais pas celle de la NPI dont il est difficile de débarrasser une exploitation sans procéder à un abattage total du cheptel. Cependant ce caractère apparemment inéluctable de la transmission de la NPI souffre des exceptions. Déjà, en 1968, WOLF et al. (b) montraient qu'il était possible de sélectionner une population indemne de virus à partir d'un stock de géniteurs infectés : dans une population où une recherche préliminaire du virus dans le liquide coelomique et les excréments avait détecté 3 femelles sur 15 et 2 mâles sur 14 porteurs de virus, les géniteurs supposés indemnes furent appariés et leur descendance élevée séparément : sur 3 couples "indemnes" deux fournirent une descendance indemne mais les descendants du $3^{\text {eme }}$ couple se révélèrent infectés. Inversement, pour deux couples "infectés", la NPI ne se déclara que dans un des lots d'alevins.

De la même façon nous avons pu observer récemment qu'à partir d'un stock de plus de 1000 géniteurs parmi lesquels 6 porteurs avaient été détectés sur un échantillon de 39. la NPI ne s'était pas déclarée ni dans le stock d'alevins obtenus dans la pisciculture, ni parmi les pontes de 12 couples différents (comprenant 2 femelles et un mâle porteursdevirus) élevées séparément au laboratoire. II faut signaler que les œufs avaient été désinfectés aussitôt après fécondation, que les porteurs n'excrétaient pas le virus dans les fèces, et que celui-ci ne fut détecté qu'au niveau du rein antérieur, de la rate ou du cerveau.

Enfin il faut mentionner la possibilité signalée par KLONTZ (1981) de couper la transmission de la NPI en effectuant fécondation et durcissement en présence d'iodophore à $25 \mathrm{mg} / \mathrm{l}$ d'iode actif. Cependant nous n'avons pas les détails des observations ou des expériences autorisant cette affirmation.

On peut conclure de ce qui précède que la transmission de la NPI n'est pas inéluctable et peut sans doute revêtir plusieurs formes, allant d'une transmission fréquente de type horizontal (contamination des ovules par les fluides séminaux au sortir de la femelle) à une transmission "interne" qui serait plus rare et reste à élucider.

\section{LA MALADIE}

\subsection{Diagnostic.}

Les symptômes et lésions provoqués par le virus de la NPI tels qu'ils ont éte définis à plusieurs reprises (par exemple WOOD, SNIESZKO et YASUTAKE, 1955 pour les souches américaines; GHITTINO et de KINKELIN, 1975 pour les souches eu:opéennes) ont été évoqués au début de cet article. Les alevins vésiculés meurent sans présenter de symptômes particuliers, et ce n'est que chez des animaux se nourrissant activement que se manifestent régulièrement la nage en vrille et surtout une boursouflure caractéristique localisée à une portion précise de l'abdomen (Fig. 3). L'histologie comme

Figure 3 : Alevins morts de Nécrose Pancréatique et alevin normal fau centre en haut). Noter le ballonnement de la région gastrique.

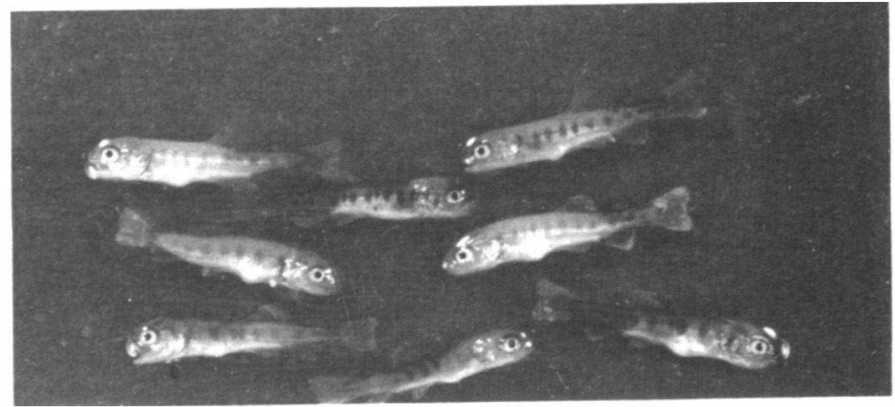

l'immunofluorescence (Mc KNIGHT et ROBERTS, 1976 ; SWANSON, 1981) désignent le pancréas comme le premier organe cible chez des animaux de un ou plusieurs mois, et les dégâts que le virus occasionne à cet organe persistent chez les survivants et apparaissent aussi chez des poissons trop âgés lors de l'infection pour présenter les 
signes cliniques. La muqueuse digestive est aussi fréquemment affectée tandis que les lésions du rein antérieur et du foie sont moins fréquentes. On peut supposer cependant que la mort des alevins vésiculés ne fait pas suite aux troubles digestifs mais à une dégradation de l'osmorégulation. Le diagnostic définitif passe par l'extraction du virus à partir des cadavres et son identification par l'effet cytopathogène qu'il provoque sur des cellules de truite en culture, puis par sa neutralisation par un sérum spécifique (GHITINO et de KINKELIN, 1975), comme il a été décrit plus haut. Il peut être compliqué par une infection simultanée par le virus de la Septicémie Hémorragique Virale. Dans de tels cas nous avons pu observer une symptomatologie mixte.

\subsection{Maladie expérimentale}

Les auteurs américains ont en général employé la transmission orale (ainsi nommée bien qu'on ne puisse affirmer que la contamination se fait effectivement per os et non par les branchies ou une autre voie) : on nourrit les animaux d'expérience avec un broyat d'alevins contaminés, ou de la nourriture artificielle imbibée d'une suspension virale.

Notre laboratoire utilise un protocole standardisé d'infection par bain: l'arrivée d'eau des aquariums est coupée, et le virus est ajouté à une concentration finale de $5 \times 10^{4}$ unités formant plage par $\mathrm{ml}$.

Les poissons sont laissés dans ce bain $3 \mathrm{~h}$ sous aération avant de rétablir l'arrivée d'eau. Ces conditions sont largement suffisantes, puisque des temps plus courts ( $1 / 2 \mathrm{~h}$ ) ou des concentrations inférieures $\left(10^{3}\right.$ ufp $\left./ \mathrm{ml}\right)$ conduisent à des courbes de mortalités identiques. Dans ces conditions, les premières mortalités apparaissent 9 - 10 jours après l'infection à $10^{\circ} \mathrm{C}$ et atteignent un maximum entre 20 et 30 jours pour cesser entre 40 et 50 jours alors que 70 à $90 \%$ des alevins ont été éliminés. Au moment du pic de mortalité l'excrétion virale peut atteindre 2.000 unités virales par alevin et par heure.

\subsection{Rôle de l’âge et de la température dans l'apparition et le développement de la maladie.}

Toutes les observations de terrain concordent pour faire de la NPI une maladie du jeune, et ceci a été confirmé par les infections expérimentales : on n'observe plus de mortalités au-delà de 20 semaines à $10^{\circ}$ chez des alevins d'omble de fontaine (VR 299 , FRANTSI et SAVAN, 1971 b) ou de truite Arc-en-Ciel. (Sp, DORSON et TORCHY, 1981). Le rôle de la température, étudié par FRANTSI et SAVAN (1971) pour la souche VR 299 , n'apparaissait pas clairement; les mortalités étaient respectivement de $0 \%\left(4,5^{\circ} \mathrm{C}\right), 74 \%$ $\left(10^{\circ} \mathrm{C}\right.$ ) et $46 \%\left(15,5^{\circ} \mathrm{C}\right)$. Nous avons observé (DORSON et TORCHY, 1981) que pour des poissons infectés à 3 et 6 semaines après éclosion et soumis à différentes conditions thermiques (Fig. 4) une température de $5,5^{\circ}$ permettait un développement très lent de la

Figure 4 : Courbes de mortalités dans des groupes de 100 alevins de Truite Arc-en-Ciel infectés par le virus de la NPI à l'âge de 3 semaines (a) ou à l'âge de 6 semaines (b), et maintenus aux températures indiquées depuis l'éclosion (d'après DORSON et TORCHY, 1981). Les mortalités dans les groupes témoins n'ont pas dépassé $10 \%$.

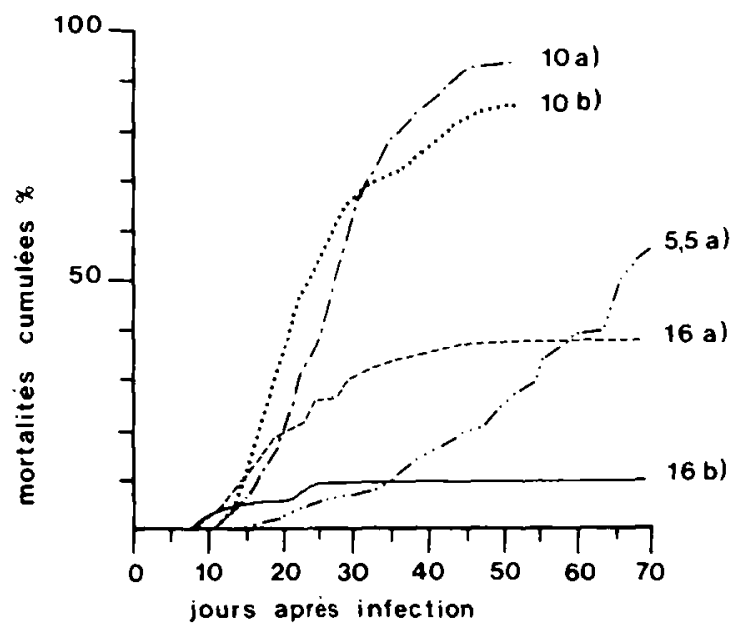


maladie mais une mortalité finale importante, tandis qu'une température de $16^{\circ}$ réduisait ou supprimait la mortalité. D'a utre part nous avons démontré une relation entre la sensibilité du poisson et son "àge physiologique " exprimé en degrés jours (Tableau 4).

Tableau 4 : Mortalité dans 3 lots d'alevins issus d'un même lot d' ceufs et ayant accumulé des nombres de degrés jours différents avant d'être ramenés à la même température et infectés ( $D^{\prime}$ après DORSON et TORCHY, 1981).

\begin{tabular}{|c|c|}
\hline Degrés x jours & $\begin{array}{c}\text { Mortalité finale } \\
\%\end{array}$ \\
\hline 600 & 80 \\
\hline 1300 & 40 \\
\hline 1850 & 8 \\
\hline
\end{tabular}

\subsection{Interférence avec la Septicémie Hémorragique Virale.}

Il a été observé, puis démontré expérimentalement (de KINKELIN et DORSON, à paraître) que l'infection de truites Arc-en-Ciel d'une dizaine de grammes, réfractaires donc à la NPl, par ce virus, les protégeait de façon très significative contre la SHV. Cette protection, acquise dès l'infection par le virus de la NPI, baisse rapidement et disparaît en quelques mois. Son mécanisme n'est pas connu, mais ne fait sans doute pas appel à l'interféron dont le virus de la NPI n'est pas inducteur, du moins chez les poissons de cette taille, et encore moins aux anticorps. Cette interférence n'empêche cependant pas les infections simultanées observées et citées plus haut, pour lesquelles on ne connaissait d'ailleurs pas la séquence d'infection.

\subsection{Nécrose Pancréatique Infectieuse et génétique.}

Bien qu'il ait été fait plusieurs fois allusion à une plus ou moins grande réceptivité de différentes souches d'une même espèce de salmonidés à la NPI, l'évidence scientifique d'une héritabilité de la résistance à cette maladie reste à apporter. Il a été seulement observé (DORSON et CHEVASSUS, résultats non publiés) que parmi 8 lots d'alevins correspondant chacun à l'insémination d'une femelle par un mâle les mortalités pouvaient varier de 42 à $94 \%$. Il reste à prouver qu'une telle hétérogénéité peut être d'origine génétique, ce qui encouragerait à la sélection de souches plus résistantes ... qui existent d'ailleurs peut-être déjà en pisciculture.

\subsection{Essais thérapeutiques.}

ECONOMON (1972) a rapporté des essais de prévention de la NPI chez des alevins d'omble de fontaine nourris avec des aliments supplémentés par un iodophore, le polyvinyl-pyrrolidone iodé, 15 jours avant le déclenchement de la maladie. Une protection notable $(24,3$ à $16,7 \%$ de mortalités suivant les doses contre $34 \%$ chez les non traités) fut enregistrée, mais il semble que peu de suites pratiques aient été données à ces expériences. SAVAN et DOBOS (1980) ont utilisé un nucléoside de synthèse, le virazole, déjà connu comme agent antiviral in vitro, administré par bain après l'infection. Là encore une baisse de mortalité (de 63 à $42 \%$ dans les meilleurs cas) fut enregistrée mais jugée insuffisante pour une application pratique. De la même façon nous avons utilisé un inducteur d'interféron déjà connu pour ses propriétés antivirales, la tilorone, à des doses différentes atteignant le seuil de toxicité sans obtenir la moindre protection. Enfin ELLIOT et AMEND (1978) ont préconisé l'acriflavine, active in vitro, mais aucun essai in vivo n'a été rapporté

\section{ESPÈCES ATTEINTES}

Dresser une liste des espèces atteintes par le virus de la NPI se heurte à une double ambiguité :

- Celle de la définition plus ou moins stricte de virus de la NPI, qui peut ou non comprendre les "virus apparentés" des invertébrés aquatiques. 
- Celle de la sensibilité réelle d'une espèce : en effet le virus peut être porté par un poisson, et même s'y multiplier sans provoquer de maladie. Pour nous il $y$ a certitude que l'espèce est sensible lorsque la maladie a pu être observée sur le terrain, et, surtout, reproduite expérimentalement par le virus isolé, ce qui réduit singulièrement la liste. Par contre la certitude inverse (qu'une espèce est insensible) est très difficile à obtenir (à cause de la variabilité des souches virales et des conditions du milieu).

Le virus a pu être isolé sur les espèces suivantes (d'après HILL et WAY, 1980):

Salmonides: Salvelinus fontinalis: Omble de Fontaine; Salmo gairdneri: Truite Arcen-Ciel; Salmo trutta : Truite Fario; Salmo clarki: Truite Fardée; Salmo salar : Saumon Atlantique; Oncorhynchus tshawytscha: Saumon Chinook. Oncorhynchus gorbuscha: Saumon Rose; Oncorhynchus kisutch:Saumon Coho; Oncorhynchus rhodurus: Amago: Oncorhynchus nerka: Saumon Nerka, Sockeye ou Kokani: Oncorhynchus masou: Yamabe: Hucho hucho:Huchon; Thymallus thymallus: Ombre.

Autres familles: Barbus barbus: Barbeau : Abramis brama :Brême; Cyprinus carpio: Carpe : Carassius carassius: Carassin; Anguilla anguilla: Anguille ; Anguilla japonica : Anguille Japonaise: Phoxinus phoxinus: Vairon: Perca fluviatilis: Perche: Esox lucius: Brochet: Rutilus rutilus: Gardon: Catostomus commersoni: Meunier noir: Brevoortia tyrannus: Hareng Atlantique.

Son pouvoir pathogène n'est certain que pour les salmonidés suivants: Omble de fontaine, Truite Arc-en-Ciel, Truite fario, Saumon Amago et Saumon sockeye. (SANO, 1973 ; YAMAZAKI, 1973).

Un virus très proche, puisqu'il est relié sérologiquement aux virus de la NPI, baptisé E.V.E., est responsable de la branchionéphrite de l'anguille sans être pathogène pour la truite (SANO, OKAMOTO et NISHIMURA, 1981).

Concernant les virus isolés en France, nous avons pu avoir des doutes concernant la Truite fario, car les activités de diagnostic du laboratoire n'avaient jamais enregistré de Nécrose pancréatique caractérisée sur des alevins de fario. Des alevins de truite Arc-enCiel et de truite fario provenant de la même pisciculture, nés le même jour et soumis à des conditions strictement identiques ont été infectés par une même dose de 2 virus de la $\mathrm{NPI}$, l'un isolé sur alevins arc-en-ciel extériorisant la maladie, l'autre sur truitelles fario (porteurs asymptomatiques). Les mortalités (Tableau 5) montrent que les deux souches virales ont tué de la même manière, mais que les alevins fario se sont montrés beaucoup plus résistants que les alevins Arc-en-Ciel. S'agit-il d'une différence au niveau des souches de poisson, ou d'une réelle différence de sensibilité d'espèce, seule une multiplication de telles expériences pourrait donner la réponse.

Tableau 5 : Mortalités enregistrées chez des alevins de Truite Fario et Arc-enCiel de 8 semaines, élevés dans les mêmes conditions et infectés avec les souches virales indiquées. Les mortalités dans les témoins non infectés étaient inférieures à $8 \%$.

\begin{tabular}{|c|c|c|}
\hline \multirow{2}{*}{$\begin{array}{c}\text { Alevins } \\
\text { infectés:espèce }\end{array}$} & $\begin{array}{c}\text { Souche virale isolée sur : } \\
\text { Truitelles Fario } \\
\text { (porteurs asymptomatiques) }\end{array}$ & Alevins \\
\hline Fario & 28 & 26 \\
\hline Arc-en-Ciel & 55 & 60 \\
\hline
\end{tabular}

De même la sensibilité du Saumon Atlantique, assurée par certains auteurs, n'était attestée par aucune preuve expérimentale. SWANSON et GILLESPIE (1979) n'avaient pas réussi la transmission expérimentale de la maladie à des alevins de 8 semaines infectés per os par la souche virale VR 299. De la même façon, nous n'avons obtenu aucune mortalité par rapport aux témoins non infectés dans des lots de 300 alevins de Saumon Atlantique de 6 semaines infectés avec une souche pathogène isolée d'Arc-en-Ciel et une autre isolée sur de jeunes Saumons Atlantique de pisciculture (porteurs asymptomatiques). Il semble donc bien que le saumon ne soit pas sensible à la $\mathrm{NPI}$, ou en tout cas aux souches employées. 


\section{IMMUNITÉ ET ESSAIS DE VACCINATION.}

Il a été reconnu très tôt que les survivants d'infection synthétisaient des anticorps sériques neutralisants, et que l'injection du virus à des animaux vierges adultes provoquait aussi une telle synthèse d'anticorps (WOLF et QUIMBY, 1969). II fut ensuite démontré que ces anticorps pouvaient transférer une immunité passive aux alevins (AGNIEL, 1975). La vaccination des alevins, dont la maturité immunologique peut être considérée comme incomplète, pouvait apparaître comme totalement irréaliste. Nous avons cependant démontré qu'il n'y avait pas d'obstacle au niveau de la compétence immunitaire : en effet, des alevins vaccinés à l'âge de 4 semaines par injection de virus pathogène inactivé par le formol sont parfaitement protégés contre l'épreuve par le virus virulent 2 semaines plus tard (Fig. 5). Par contre les autres modes d'administration (bain après choc osmotique, ingestion) se sont révélés inefficaces (DORSON, 1977b; HILL, DORSON et DIXON, 1980). Les seuls espoirs de vaccination pratique résident dans l'utilisation de vaccins vivants (virus atténués) et les différents essais ont été rapportés (HILL, DORSON et DIXON, 1980). On peut les résumer comme suit. Le virus non pathogène obtenu par passages successifs en cellules de Truite (DORSON, CASTRIC et TORCHY, 1978) ne confère aucune immunité, et ceci est corroboré par une bien moins bonne immunogénicité chez la truite adulte (HILL et DORSON, résultats non publiés). II en est de mème pour le virus $A b$, qui peut de plus entraîner une mortalité non négligeable. Des variants non pathogènes ont été obtenus en cultivant la souche pathogène à température croissante $\left(18\right.$ puis $\left.20^{\circ} \mathrm{C}\right)$ sur cellules de truite et en présence de sérum de truite. Ces variants se sont révélés incapables d'infecter les poissons, et par conséquent de provoquer la moindre immunité. Les seuls résultats encourageants, bien qu'inconstants, ont été obtenus avec une souche virale isolée sur Perche en GrandeBretagne et qui a conféré une protection notable dans certaines expériences (HILL. DORSON et DIXON, 1980 ).

Figure 5 : Enveloppe des différentes courbes de mortalité obtenues chez des alevins de Truite Arc-en-Ciel infectés à l'âge de 6 à 7 semaines par le virus de la NPI (temps 0) (sauf le groupe C, représentant les témoins non infectés). Le groupe a) correspond aux témoins non vaccinés et aux traitements suivants effectués à l'âge de 3 à 4 semaines: préinfection avec un variant ayant perdu son pouvoir pathogène, bain dans le virus inactivé au formol ou ingestion de ce dernier, administration des protéines obtenues après dégradation du virus par bain ou injection péritonéale, injection de cellules normales RTG 2 formolées. b) Injection intrapéritonéale du virus pathogène inactivé par le formol.

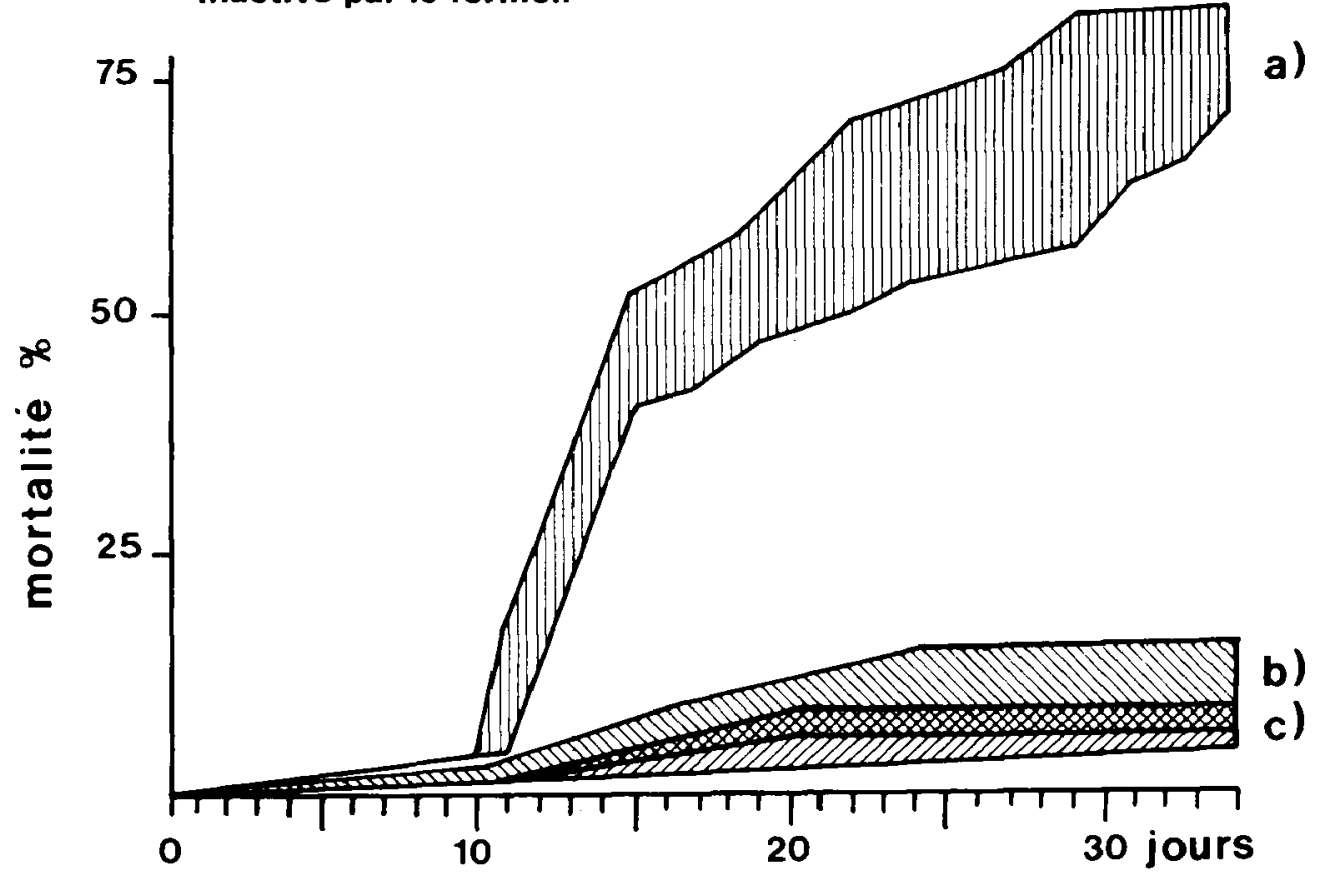




\section{CONCLUSIONS ET PERSPECTIVES.}

Les connaissances concernant la NPI ont notablement progressé ces 10 dernières années, et, fait important, nous avons acquis nombre d'informations intéressantes concernant les souches européennes, qui présentent des caractères originaux par rapport au prototype nord-américain. La grande variété qui se fait jour dans les virus de la NPI, l'allongement constant de la liste des hôtes possibles, représentent un point majeur qui ne simplifiera pas les travaux futurs, quelle que soit leur finalité. L'aspect qui nous semble actuellement le plus digne de développement, parce qu'il a été très négligé jusqu'à présent, est l'épidémiologie de la NPI en France : quelle est la répartition de la maladie, comment se fait la transmission et comment peut-on la couper, quelle est son incidence exacte sur la truite fario. La prophylaxie sanitaire de la NPI est bien plus difficile à réaliser que celle de la SHV mais reste possible: nous avons des exemples de piscicultures ayant éliminé cette maladie

II faut insister sur le rôle bénéfique d'une élévation de température jusqu'à $16^{\circ} \mathrm{C}$ dans l'évolution de la maladie comme dans le raccourcissement de la période de réceptivité. Le chauffage de l'eau avec recyclage partiel et filtration sur sable apparaît comme une solution qui mériterait d'être employée.

A plus long terme, la génétique permettra peut-ètre de réduire l'incidence de la NPI par la sélection de souches plus résistantes. La vaccination reste théoriquement possible, mais ne pourra guère se faire que grâce à un vaccin vivant, et la souche vaccinante reste à trouver. Plusieurs laboratoires s'y emploient et tout espoir n'est pas perdu. On peut donc prédire sans trop de risques que l'arsenal technique pour lutter contre cette maladie va se développer.

\section{REMERCIEMENTS}

Les travaux du laboratoire exposés au cours de cette revue ont été largement soutenus par une participation financière du Conseil Supérieur de la Pêche (contrat $n^{\circ} 65 / 1.278$ ), et l'utilisation par l'INRA de la pisciculture de Gournay Sur Aronde. Les alevins Arc-en-Ciel et Fario utilisés ont été fournis en majeure partie par M.A.MARTENS, pisciculture domaniale de Neuville Ste Gemme, et les alevins de Saumon Atlantique par M. HOLL de la $1^{\text {ere }}$ région piscicole.

\section{BibliographIE}

AGNIEL L.D., 1975. An assessment of passive transfer of immunity to Infectious Pancreatic Necrosis Virus (IPNV) in Trout. M.S. Thesis. The American University, Washington, D.C.

AHNE W., 1978. Isolation and characterization of Infectious Pancreatic Necrosis Virus from Pike (Esox lucius). Archives of Virology, 58: 65-69

AMEND D.F., PIETSCH J.P., 1972. Virucidal activities of two iodophors to salmonid viruses. J. Fish. Res. Board. Can. 29:61-65

BAUDOUY A.M., 1976. Données expérimentales sur la rémanence du virus de la Nécrose Pancréatique infectieuse des salmonidés dans l'environnement aquatique. Ann. Rech. Véter. 7 (1): 75-82.

BESSE P., de KINKELIN P., 1965. Sur l'existence en France de la Nécrose Pancréatique de la Truite Arc-en-Ciel (Salmo gairdneri) Bull. Ac. Vet. Fr. 38: 185-190.

BILLI J.L., WOLF K., 1969. Quantitative comparison of peritoneal washes and feces for detecting Infectious Pancreatic Necrosis (IPN) Virus in carrier Brook trout. J. Fish Res. Board. Can. 26 (6): 1459-1465.

BULLOCK G.L., RUCKER R.R., AMEND D., WOLF K., STUCKEY H.M., 1976. Infectious Pancreatic Necrosis: transmission with lodine treated and non treated eggs of Brook trout (Salvelinus fontinalis). J. Fish. Res. Board. Can. 33 (5) : $1197-1198$.

DESAUTELSD., Mac KELVIE R.M., 1975. Practical aspects of survival and destruction of Infectious Pancreatic Necrosis Virus. J. Fish. Res. Board. Can. 32 (4) : 523-531.

DOBOS P., HILL B.J., HALLETT R., KELLS D.T., BECHT H., TENINGES D., 1979. Biophysical and biochemical characterization of five animal viruses with bisegmented double-stranded RNA genomes. J. Virol. 32 (2) : 593-605. 
DORSON M., 1977 a. Infectious Pancreatic Necrosis of salmonidae. Recent developments and future prospects. Vet. Sci. Commun. $1: 201-212$.

DORSON M., 1977 b. Vaccination trials of rainbow trout fry against Infectious Pancreatic Necrosis. Bull. de l'Off. int. Epiz. 87(5-6): 405-406.

DORSON M., CASTRIC J., TORCHY C., 1978. Infectious Pancreatic Necrosis Virus of salmonids: biological and antigenic features of a pathogenic strain and of a non-pathogenic variant selected in RTG 2 cells. Journal of Fish Diseases 1 : 309-320.

DORSON M., de KINKELIN P., TORCHY C., 1975. Virus de la Nécrose Pancréatique Infectieuse: acquisition de la sensibilité au facteur neutralisant du sérum de truite après passages successifs en culture cellulaire. C.R. Acad. Sc., Série D, 281 : 1435-1438

DORSON M., TORCHY C., 1981. The influence of fish age and water temperature on mortalities of rainbow trout (Salmo gairdneri Richardson)caused by a European strain of Infectious Pancreatic Necrosis Virus. Journal of Fish Diseases 4 : 213-221

ECONOMON P.P., 1972. Polyvinyl pyrrolidone-iodine as a control for Infectious Pancreatic Necrosis of Brook trout. F.I. EIFAC 72/SC II. Symp. 13.

ELLIOT D.G., AMEND D.F., 1978. Efficacy of certain desinfectants against Infectious Pancreatic Necrosis Virus. J. Fish. Biol. 12: 277-286.

FIJAN N.N., GIORGETTI, 1978. Infectious Pancreatic Necrosis: isolation of virus from eyed eggs of rainbow trout Salmo gairdneri Richardson. Journal of Fish Diseases 1 (3): $269-270$.

FINLAY J., HILL B.J., 1975. The use of the complement fixation test for rapid typing of Infectious Pancreatic Necrosis Virus. Aquaculture 5 : 305-310.

FRANTSI C., SAVAN M., 1971 a. Infectious Pancreatic Necrosis Virus: comparative frequencies of isolation from feces and organs of Brook trout /Salvelinus fontinalis). J. Fish. Res. Board. Can. 28 (7): 1064-1065.

FRANTSI C., SAVAN M., 1971 b. Infectious Pancreatic Necrosis Virus. Temperature and age factors in mortality. Journal of Wildlife Diseases 7 : 249-255.

GHITTINO P., de KINKELIN P., 1975. Proposed control measures for the principal contagious diseases of fish. Bull. Off. int. Epiz. 83 (7-8): 689-715.

GRAVELL M., MALSBERGER R.G., 1965. A permanent cell line from the fathead minnow (Pimephales promelas). Ann. N.Y. Acad. Sci. $126: 555-565$.

HILL B.J., DORSON M., DIXON P.F., 1980. Studies on immunization of trout against IPN. In Fish Diseases. Third COPRAQ-Session. W. Ahne Ed., SpringerVerlag. 252 p.

HILL B.J., WAY K., 1980. Properties and interrelationship of bisegmented doublestranded RNA viruses of fish and shellfish. Proceedings of the Conference on Aquatic Animals Viruses, 22 Mai 1980, Institut Pasteur, Paris, 22-24.

KLONTZ, 1981. Conférence au Syndicat des Pisciculteurs-Salmoniculteurs de France à Paris, le 10 juin 1981.

Mac DONALD R.D., GOWER D.A., 1981. Genomic and Phenotypic divergence among three serotypes of aquatic Birnaviruses (Infectious Pancreatic Necrosis Virus). Virologr 114: 187-195.

Mac GONIGLE R.H., 1940. Acute catarrhal enteritis of salmonid fingerlings. Trans. Am. Fish. Soc. $70: 297$.

Mac KELVIE R.M., DESAUTELS D., 1975. Fish viruses. Survival and inactivation of Infectious Pancreatic Necrosis Virus. J. Fish. Res. Board. Can. 32 (8) : 1267-1273.

Mac KNIGHT I.J., ROBERTS R.J., 1976. The pathology of Infectious Pancreatic Necrosis. I. The sequential histopathology of the naturally occuring condition. Br. Vet. J. $132: 76$.

MAISSE G., DORSON M., TORCHY C., 1980. Inactivation de deux virus pathogènes pour les salmonidés (virus de la Nécrose Pancréatique Infectieuse et de la Septicémie Hémorragique Virale) par les rayons ultraviolets. Bull. Fr. Pisc. 278 : 34-40.

MUNRO A.L.S., LIVERSIDGE J., and ELSON K.G.R., 1976. The distribution and prevalence of Infectious Pancreatic Necrosis Virus in Wild Fish in Loch Awe. 
Proceedings of the Royal Society of Edinburgh Section B (Natural Environment), Vol. 75, part. $4: 223-232$

NICHOLSON B.L., POCHEBIT S., 1981. Antigenic analysis of Infectious Pancreatic Necrosis Viruses (IPNV) by neutralization kinetics. Develop. Biol. Standard. 49 35-41 (S.Karger, Basel).

NICHOLSON B.L., THORNE G.W., JANICKI C., 1979. Studies on a host range variant from different isolates of Infectious Pancreatic Necrosis Virus. Journal of Fish Diseases $2: 367-379$

PIPER D., NICHOLSON B.L., DUNN J., 1973. Immunofluorescent study of the replication of Infectious Pancreatic Necrosis Virus in Trout and Atlantic Salmon cell cultures Infect. Immunity 8 (2): 249-254.

SANO T., 1973. Studies on viral diseases of Japanese fishes. IV. Infectious Pancreatic Necrosis of Rainbow trout: susceptibility of fresh water salmons of genus Oncorhynchus. Bull. Jap. Soc. Sci. Fish. 39(2): 117

SANO T., YAMAZAKI T., 1973. Studies on viral diseases of Japanese fishes. V. Infectious Pancreatic Necrosis of Amago trout. Bull. Jap. Soc. Sci. Fish. 39(5): 477-480.

SANO T., OKAMOTO N., NISHIMURA T., 1981. A new viral epizootic of Anguilla japonica Temminck and Schlegel. Journal of Fish Diseases 4 (2): 127-139.

SAVAN M., DOBOS P., 1980. Effect of virazole on Rainbow trout Salmo gairdneri Richardson fry infected with Infectious Pancreatic Necrosis virus. Journal of Fish Diseases 3 (5): 437-440.

SCHERRER R., COHEN J., 1975. Studies on Infectious Pancreatic Necrosis Virus interactions with RTG 2 and FHM cells: selection of a variant virus type in FHM cells. J. Gen. Virol. 28 : 9-20.

SNIESKO S.F., WOOD E.M., YASUTAKE W.T., 1957. Infectious Pancreatic Necrosis in Trout. A.M.A. Arch. Pathol. 63: 229-233.

SWANSON R.N., 1981. Use of the indirect fluorescent antibody test to study the pathogenesis of Infectious Pancreatic Necrosis Virus infection in trout. Fish biologics: serodiagnostics and vaccines. Develop. Biol. Standard. 49: 71-77 (S. KARGER, Basel).

SWANSON R.N., GILLESPIE J.H., 1979. Pathogenesis of Infectious Pancreatic Necrosis in Atlantic Salmon (Salmo salar). J. Fish. Res. Board. Can. 36 (5): 587-591.

TU K., SPENDLOVE R.S., GOEDE R.W., 1975. Effect of temperature on survival and growth of Infectious Pancreatic Necrosis virus. Infection and Immunity $11(6)$ : 1409-1412.

VESTERGARD-JORGENSEN P.E., 1972. Freund's adjuvants: their influence on the specificity of viral antisera. Acta Path. Microbiol. Scand. Section B 80: 931-933.

VESTERGARD-JORGENSEN P.E., KEHLET N.P., 1971. Infectious Pancreatic Necrosis (IPN) viruses in danish rainbow trout : their serological and pathogenic properties. Nord. Vet. Med. 23: 568-575.

WOLF K., 1972. Advances in fish virology: a review 1966-1971. Symp. Zool. Soc. Lond. $30: 305-331$

WOLF K., BULLOCK G.L., DUNBAR C.E., OUIMBY M.C., 1968a). Viral diseases of freshwater fishes and other lower vertebrates : comparative studies on IPN virus. Progr. Sport. Fish. Res. 77 : 138-140.

WOLF K., MANN J.A., 1980. Poikilotherms Vertebrate cell lines and viruses : a current listing for fishes. In Vitro 16(2): 168-179.

WOLF K., QUIMBY M.C., 1962. Established eurythermic line of fish cells in vitro Science 135: 1065-1066.

WOLF K., QUIMBY M.C. 1967. Infectious Pancreatic Necrosis (IPN): its diagnosis, identification, detection and control. Riv. it. piscic. ittiopat. 2 (4): $76-78$.

WOLF K., QUIMBY M.C., 1969. Infectious Pancreatic Necrosis: clinical and immune response of adult trouts to inoculation with live virus. J. Fish. Res. Board. Can. 26: $2511-2516$

WOLF K., QUIMBY M.C., 1971. Salmonid viruses : Infectious Pancreatic Necrosis virus Morphology. Pathology and Serology of first european isolations. Archiv. für die Gesamte Virus Forschung 34: 144-156 
WOLF K., QUIMBY M.C., BRADFORD A.D., 1963. Egg-Associated transmission of IPN virus of trouts. Virology $21(3): 317-321$.

WOLF K., QUIMBY M.C., CARLSON C.P., BULLOCK G.L., 1968 b). Infectious Pancreatic Necrosis: selection of virus-free stock from a population of carrier trout. J. Fish. Res. Board. Can. 25(2): 383-391.

WOLF K., SNIESZKO S.F., DUNBAR C.E., PYLE E., 1960. Virus nature of Infectious Pancreatic Necrosis in trout. Proc. Soc. Exper. Biol. Med. 104: 105-108.

WOOD E.M., SNIESZKO S.F., YASUTAKE W.T., 1955. Infectious Pancreatic Necrosis in Brook Trout. A.M.A. Arch. Pathol. 60: 26-28.

YAMAMOTO Y., 1975 a). Infectious Pancreatic Necrosis (IPN) virus carriers and antibody production in a population of rainbow trout/Salmo gairdneri). Canadian Journal of Microbiology 21 (9) : 1343-1347.

YAMAMOTO T., $1975 \mathrm{~b}$ ). Frequency of detection and survival of infectious Pancreatic Necrosis virus in a carrier population of Brook Trout (Salvelinus fontinalis) in a lake. J. Fish. Res. Board. Can. 32(4) : 568-570.

YAMAMOTO T., KILISTOFF J., 1979. Infectious Pancreatic Necrosis virus. Quantification of carriers in lake populations during a 6-year period. J. Fish. Res. Board. Can. $36(5): 562-567$. 